\title{
CONSTRUÇÃO CIVIL E RESÍDUOS SÓLIDOS: COLETA E DISPOSIÇÃO FINAL NO MUNICÍPIO DE PRESIDENTE PRUDENTE-SP ${ }^{1}$
}

\author{
Edilene Mayumi Murashita Takenaka²
}

Alba Regina Azevedo Arana ${ }^{3}$

Mayara Pissutti Albano ${ }^{4}$

Resumo: O crescimento populacional e sua concentração nos centros urbanos trouxe, como consequência, a expansão das atividades ligadas à construção civil. Seja para atender a demanda por moradias, áreas de lazer, postos de atendimento à população ou mesmo para o comércio em crescente dinamismo, a construção civil tem ampliado sua participação na dinâmica da produção urbana e, consequentemente, a geração de resíduos oriunda dessa atividade, também. Entender a maneira como o município enfrenta a situação de geração de resíduos da construção civil, sua coleta e disposição final, apresenta-se como fator primordial a fim de contribuir para a elaboração de um adequado gerenciamento de resíduos sólidos da construção civil no município de Presidente Prudente-SP. A metodologia utilizada foi o levantamento de dados a partir da

\footnotetext{
${ }^{1}$ Este trabalho faz parte das discussões sobre o capítulo 5 da Tese de Doutoramento de Takenaka (2008) realizado pelo grupo de estudos e pesquisas "Sociedade, Meio Ambiente e Desenvolvimento Regional" SOMADRE, do Mestrado em Meio Ambiente e Desenvolvimento Regional - MMADRE da Unoeste de Presidente Prudente - SP.

2 Doutora em Geografia - Unesp, Docente do Mestrado em Meio Ambiente e Desenvolvimento Regional da Unoeste (edilene@unoeste.br)

${ }^{3}$ Doutora em Geografia - Usp, Docente do Mestrado em Meio Ambiente e Desenvolvimento Regional da Unoeste, (alba@unoeste.br)

${ }^{4}$ Bacharel em Arquitetura - Unoeste, Mestranda em Meio Ambiente e Desenvolvimento Regional na Unoeste(mayara_albano@hotmail.com)
} 
documentação direta e indireta, bem como a adoção da técnica da observação direta intensiva e entrevistas realizadas junto a órgãos públicos municipais.

Palavras-chave: Construção civil. Resíduo sólido. Gerenciamento.

\section{INTRODUÇÃO}

O processo de urbanização pode ser caracterizado pelo deslocamento de moradores da área rural para áreas urbanas e está intimamente associado ao desenvolvimento da civilização e da tecnologia. Tal fenômeno culmina com a redistribuição das populações das zonas rurais para as cidades em busca de melhores condições de vida.

Desencadeada inicialmente na Europa do século XVIII, como consequência da Revolução Industrial, a urbanização da maior parte dos países desenvolvidos industrializados veio a ocorrer a partir da segunda metade do século XIX.

A industrialização crescente e a intensidade do progresso tecnológico consolidaram a atividade industrial como essencialmente urbana, ocasionando uma grande migração dos trabalhadores rurais que, expulsos pela mecanização no campo, optaram por partir para as cidades, atraídos pela possibilidade de melhores condições de vida.

O processo de urbanização em solo brasileiro, teve início com algumas décadas de atraso, mais precisamente em meados do século XX com o aumento da população e o desenvolvimento do espaço urbano em que, moradores das áreas rurais passaram a buscar as cidades objetivando encontrar mais e melhores opções de trabalho e acesso à saúde e educação, surgindo assim, uma correlação imediata entre emprego e o inchaço nos centros urbanos. (SANTOS, 1998)

Ainda, segundo Santos (1998), podemos afirmar que, no Brasil, ocorreu um dos mais rápidos processos de urbanização do mundo: em 1940 as cidades abrigavam 46\% da população do país, em 1975 esse índice já era de 61\%, em 1991 apresentava-se em 75\% 
e a previsão da ONU (Organização das Nações Unidas) é de que em 2025 esse índice atinja $88 \%$.

A concentração populacional nas áreas urbanas trouxe alguns desequilíbrios na medida em que houve a ampliação da demanda por moradias, alimentação, escolas, hospitais, saneamento básico entre outros, exigindo um planejamento urbano nem sempre presente nos centros urbanos.

De acordo com Deák \& Schiffer (1999) e Ojima (2007), quando nos referimos ao processo de crescimento urbano, dois fatores devem ser considerados: o populacional e 0 padrão de expansão física das ocupações urbanas.

O fator populacional representa um desafio em si mesmo quando exerce um importante peso na expansão da infraestrutura urbana. Já o fator de expansão física das ocupações urbanas deve ser entendido como essencial para que esse crescimento possa se dar com maior ou menor custo social, refletindo impactos sobre as formas de reprodução social e a sustentabilidade ambiental.

Segundo Takenaka (2008, p.2):

A crescente concentração da população brasileira, nos centros urbanos, traz a necessidade de atender a novas demandas por bens de consumo sejam eles, duráveis ou não-duráveis. Tal concentração, quando não acompanhada de um planejamento adequado, contribui para o agravamento de uma das principais características das atividades humanas: a geração de resíduos.

Dessa forma, podemos dizer que o processo de urbanização e o consequente aumento da população nos centros urbanos, traz o surgimento de novas demandas por moradias, áreas de lazer, de atendimento às necessidades básicas da população e de comércio. Temos, assim, a ampliação das construções civis e, consequentemente, a geração de resíduos oriundos dessa atividade.

Reforçando essa constatação, temos as contribuições de Oliveira (2004), Eigenher (1999) e Magera (2003) que são unânimes ao afirmar que qualquer atividade humana tem por consequencia a geração de resíduos, seja ao se alimentarem, ao construírem seus lares, ao se distraírem com atividades de lazer ou, principalmente, ao produzirem mercadorias e serviços. 
Segundo Pinto (2005), estudos realizados em alguns municípios apontam que os resíduos da construção formal têm uma participação entre $15 \%$ e $30 \%$ na massa dos resíduos da construção e demolição, reforçando a afirmação dentre vários profissionais da área sobre o desperdício de materiais na construção civil.

\section{RESÍDUOS DA CONSTRUÇÃO CIVIL: GERAÇÃO E GERENCIAMENTO}

O Instituto de Pesquisas Tecnológicas (D’Almeida e Vilhena, 2000) aliado aos conceitos apresentados pela Associação Brasileira de Normas Técnicas - ABNT, através da NBR 10.004/87, e em sua nova versão, emitida em 2004, juntamente com a obra de Teixeira (2001), oferece uma caracterização dos resíduos de acordo com sua fonte geradora.

Dessa forma, classificamos o resíduo da construção civil e demolição como resíduos gerados na construção, reforma ou demolição de edificações ou obras de infra-estrutura urbana.

Tal classificação possui grande significado não só em termos de tipificação do resíduo, mas também no que se refere à responsabilização sobre o mesmo.

A construção civil apresenta-se como uma atividade produtiva geradora de resíduos sólidos em grandes quantidades devido ao desperdício de materiais ocorrido nos próprios canteiros de obras ${ }^{5}$.

De acordo com Pinto (2005), cerca de $75 \%$ dos resíduos gerados pela construção civil nos municípios tem sua origem em eventos informais realizadas pelos próprios usuários de imóveis, são eles: obras de construção, reformas e demolições.

Souza et all (sd.) apresenta um estudo que ilustra as perdas oriundas de um canteiro de obras envolvendo suas diferentes fases. Tais perdas ocorrem desde a concepção do empreendimento, passam por sua execução e culminam na fase da

\footnotetext{
${ }^{5}$ Segundo estudo realizado pela UFMG intitulado Alternativas para a Redução do Desperdício de Materiais nos Canteiros de Obras, uma das maiores causas do desperdício nas construções está no próprio layout dos canteiros e à mão-de-obra desqualificada. Disponível em: http://perdas.pcc.usp.br/. Acesso em 24/10/2012.
} 
utilização e referem-se à diferença entre a quantidade de material previsto no projeto e a quantidade efetivamente utilizada.

Podemos deduzir que em todas as fases de um empreendimento ocorrem perdas de materiais que, somadas às perdas (materiais sólidos que sobram em suas diversas fases e que, uma vez incorporados e não utilizados somam-se à quantidade de entulho gerado) dos demais empreendimentos no município necessitam de um adequado gerenciamento e disposição final.

A inadequada disposição final dos resíduos sólidos da construção civil traz inúmeros problemas ao município, principalmente aqueles envolvendo impactos ambientais, tais como:

- degradação das áreas de manancial e de proteção permanente;

- proliferação de agentes transmissores de doenças;

- assoreamento de rios e córregos;

- obstrução dos sistemas de drenagem (galerias, sarjetas, etc);

- ocupação de vias e logradouros públicos por resíduos, com prejuízo à circulação de pessoas e veículos,

- além da própria degradação da paisagem urbana;

- existência e acúmulo de resíduos que podem gerar risco por sua periculosidade.

O poder público municipal deve exercer papel fundamental na busca por conscientizar e disciplinar geradores de resíduos da construção civil e agentes responsáveis pela sua disposição final.

A falta de efetiva prática de disciplina e ordenamento imposta por políticas públicas do município no que se refere aos fluxos dos resíduos da construção civil, bem como o descompromisso dos agentes geradores no manejo e destinação final dos mesmos são as causas de inúmeros problemas ambientais.

Cada etapa envolvida na cadeia da construção civil gera elevados índices de descarte que podem ser fruto dos procedimentos de produção de materiais de construção, rejeitos da construção, propriamente dita ou ainda, resultado do pós-uso através das demolições.

Segundo o D'Almeida e Vilhena (2000), genericamente denominamos os resíduos da construção civil como "entulho" e podemos definí-los como "o conjunto de fragmentos ou restos de tijolo, concreto, argamassa, aço, madeira, entre outros, provenientes do 
desperdício na construção, reforma e/ou demolição de estruturas como prédios, residências e pontes".

Embora a maior parte desses resíduos seja inerte e, portanto, não contaminante, é fundamental o seu papel, quando se trata de questões ambientais, dado o seu grande volume e condições favoráveis para a proliferação de insetos e roedores quando, inadequadamente, disposto.

Além disso, como normalmente os municípios não coletam o entulho gerado, é muito comum o despejo em áreas clandestinas, vias públicas, terrenos baldios e até margens de rios, trazendo diversos transtornos como: a geração de depósitos instáveis passíveis de deslizamentos quando lançados em encostas ou terrenos problemáticos e ou, levando à obstrução do escoamento pluvial e provocando inundação, quando lançado em terras baixas. (D'ALMEIDA e VILHENA, 2000)

Até 1998, o município de Presidente Prudente-SP tratava da disposição final de resíduos da construção civil como a grande maioria dos municípios brasileiros: lançamento aleatório em áreas de preservação ambiental, tais como: fundos de vales, nascentes, ou mesmo ao longo das estradas. (HENARES, 2006).

A preocupação, com tal situação, mostrou-se operante após a Lei 5190/98 que trata do serviço de recolhimento de entulhos e dá outras providências e que, em seu artigo $2^{\circ}$ estabelece que: cabe ao particular a remoção de entulhos para locais, previamente, determinados pela Secretaria Municipal de Planejamento.

Dessa maneira, a responsabilidade sobre a coleta dos resíduos de construção civil e de bens móveis, inservíveis, incide sobre os geradores desses materiais, motivo pelo qual, a PRUDENCO 6 não presta tal serviço. Os particulares, geradores desses materiais, contratam o serviço de empresas especializadas ${ }^{7}$ que se utilizam de caçambas para fazerem a coleta e o transporte dos resíduos de seu local de origem até os locais prédeterminados para sua disposição final.

Até o final de 2007 existiam 4 áreas de propriedade da Prefeitura Municipal, chamadas "bolsões de entulho", disponibilizadas para a disposição desses resíduos,

\footnotetext{
${ }^{6}$ PRUDENCO - Companhia Prudentina de Desenvolvimento - Empresa de economia mista.

${ }^{7}$ Essas empresas pagam uma taxa para a prefeitura municipal e se comprometem junto à SEMAV.
} 
localizadas em áreas próximas ao Estádio Prudentão, do Distrito Industrial, ao SESI (na Vila Furquim) e à Escola de Curtimento de Couro.

Segundo o Secretário de Assuntos Viários ${ }^{8}$, atualmente, existe apenas um bolsão disponível no município. Os demais pontos foram fechados por terem se tornado inadequados devido à proximidade da área urbana.

Quando apropriado, Prefeitura Municipal utiliza os restos fragmentados do entulho para a pavimentação de algumas ruas e estradas de terra do município e, também, para a pavimentação das vias de acesso à área do aterro controlado no Distrito Industrial.

Pela sua natureza e composição, os resíduos de construção civil prestamse a diversas formas de reutilização. Para isso, é econômica e ambientalmente interessante que se interliguem segmentos produtivos, de tal forma que os rejeitos se transformem em subprodutos de terceiros. Assim, parcela significativa do que hoje é descartado, potencialmente gera receita. Uma das formas mais abrangentes de reciclagem é a de utilização da parcela de resíduos [...] destinando-a à pavimentação urbana. (GOLDENSTEIN, 2005, p.94)

Entretanto, há situações especiais em que os proprietários de terrenos acidentados e com graves problemas de erosão, solicitam à Prefeitura Municipal que os resíduos da construção civil sejam dispostos, durante período pré-determinado, em suas propriedades como uma alternativa para aterrar as valas e voçorocas existentes, sem incorrer em custos maiores. Como exemplo, podemos citar a antiga área de disposição de resíduos sólidos na Vila Furquim, próxima ao SESI.

Segundo Takenaka (2008), apesar da regulamentação, acerca da disposição de entulho e da promoção de reutilização dos materiais, é importante ressaltar que apenas uma pequena parcela é separada, ao chegar nos bolsões de entulho, para ser reaproveitada. Associada à falta de uma separação adequada, em termos quantitativos, não podemos deixar de citar que, como toda cidade, Presidente Prudente sofre com a disposição clandestina ${ }^{9}$ de resíduos da construção civil.

\footnotetext{
${ }^{8}$ Entrevista concedida ao Jornal Oeste Notícias, 26/04/2008,Caderno Geral, p.1.3.

9 Talvez para poupar tempo ou para reduzir o gasto com combustível, algumas empresas depositam o entulho coletado em locais não permitidos para tais fins, ou seja em locais impróprios para o recebimentos desses resíduos, mesmo correndo o risco das penalidades impostas à infração.
} 
Segundos os funcionários municipais, responsáveis pela Secretaria de Obras de Presidente Prudente, mesmo com a possibilidade de aplicação de multas aos infratores, algumas empresas e até mesmo agentes particulares se arriscam a jogar o entulho em locais considerados inadequados, pela legislação vigente, pois contam com o fato da fiscalização, desses atos ser precária e de difícil mensuração.

De acordo com os funcionários municipais entrevistados, um fator muito importante para combater o depósito clandestino de entulho é a conscientização e a posterior colaboração da própria população prudentina. Contudo, acreditam ser um processo longo e de difícil realização.

\section{CONSIDERAÇÕES FINAIS}

Acreditamos que, com a prática de disposição desses resíduos em locais adequados (reduzindo a disposição clandestina) e uma melhor separação de materiais, as possibilidades de reaproveitamento desse tipo de resíduo poderiam contribuir, de maneira significativa, para a conservação do meio ambiente e o barateamento de algumas obras voltadas à construção civil.

Salientamos que, com a prática de disposição desses resíduos em locais adequados (reduzindo a disposição clandestina) e uma melhor separação de materiais, as possibilidades de reaproveitamento desse tipo de resíduo poderiam contribuir, de maneira significativa, para a conservação do meio ambiente e o barateamento de algumas obras voltadas à construção civil.

A própria administração do município mostra-se inclinada à implantação de projetos ligados ao reaproveitamento de restos da construção civil como pudemos observar em reunião realizada no dia 21/09/2007, no Paço Municipal de Presidente Prudente, quando o, então prefeito, afirmou ter solicitado aos órgãos municipais competentes, um estudo sobre usinas de reciclagem e reaproveitamento dos resíduos da construção civil. 
O estudo solicitado ainda é apenas uma idéia sem nada concreto a ser apresentado, mas demonstra o início de um processo de conscientização que, a longo prazo, pode trazer muitos benefícios ao município.

\section{REFERENCIAS BIBLIOGRÁFICAS}

D'ALMEIDA, M. L. O.; VILHENA, A. (coord.) Lixo municipal: manual de gerenciamento integrado. 2 2eㅡ. ed. São Paulo: IPT/CEMPRE, 2000. - (Publicação IPT 2622).

DEÁK, C. \& SCHIFFER, S. R. (Orgs.). O processo de Urbanização no Brasil. 1. ed., São Paulo: EDUSP, 1999.

EIGENHEER, E. M. Lixo e vanitas: considerações de um observador de resíduos. 1999. Tese (Doutorado em Educação). Faculdade de Educação, Universidade Federal Fluminense, Niterói, 1999.

GOLDENSTEIN, S. Gestão racional e valoriazação de resíduos de construção civil e demolições. In CAMPOS, Jayme de Oliveira \& BRAGA, Roberto (org.) Gestão de resíduos: valorização e participação. Rio claro: Deplan/ IGCE/UNESP, 2005. pág 91-95.

HENARES, E. L. Política municipal do meio ambiente: estudo aplicado ao município de Presidente Prudente. 1999. 83p. Trabalho de conclusão de curso (Graduação em Geografia) - Faculdade de Ciências e Tecnologia, Universidade Estadual Paulista, Presidente Prudente, 1999

MAGERA, M. Os empresários do lixo: um paradoxo da modernidade. Campinas: Átomo, 2003.

OJIMA, Ricardo. Dimensões da urbanização dispersa e proposta metodológica para estudos comparativos: uma abordagem socioespacial em aglomerações urbanas brasileiras. Rev. bras. estud. popul., São Paulo, v. 24, n. 2, Dec. 2007

OLIVEIRA, A. S. D. de. Método para viabilização da implantação de plano de gerenciamento integrado de resíduos sólidos: o caso do município do Rio Grande-RS. 2002. 230p. Tese (Doutorado em Engenharia de Produção) - Engenharia da Produção, Universidade Federal de Santa Catarina, Florianópolis, 2002

PINTO, T. P. (coord.) Gestão ambiental de resíduos da construção civil: a experiência do Sinduscon-SP. São Paulo: Obra Limpa: I \& T: Sinduscon-SP, 2005 
SANTOS, M. A urbanização brasileira. 1. ed., São Paulo: HUCITEC, 1998.

SOUZA, U. E. L. et all. Perdas de materiais nos canteiros de obras: a quebra do mito. sd. Disponível em:

http://www.gerenciamento.ufba.br/MBA\%20Disciplinas\%20Arquivos/Produtividade/Perdas \%20Revista\%20Qualidade.pdf . Acesso em 24/10/2012.

TAKENAKA, E. M. M. Políticas Públicas de Gerenciamento Integrado de Resíduos Sólidos Urbanos no Município de Presidente Prudente-SP. Presidente Prudente: FCT, UNESP, 2008, 232f. Tese (Doutorado) - Faculdade de Ciências e Tecnologia, Universidade Estadual Paulista, 2008.

TEIXEIRA, B.A. do N. Gestão dos Resíduos sólidos: desafio para as cidades. In CARVALHO, P.F. de \& BRAGA, R. (org.) Perspectivas de gestão ambiental em cidades médias. Rio Claro: UNESP-IGCE-Laboratório de Planejamento Municipal-DEPLAN, 2001. 